\title{
Understanding the Choices That Patients Make
}

\author{
Thomas R. Taylor, $M D, P b D$
}

Several developments in health care in recent years have focused attention on the patient's role in his or her own health care. Patients are demanding greater participation in the decision making that surrounds their care. More and more of the financial responsibility for their care falls on their own shoulders. Drug companies promote their products through the lay media directly to patients, bypassing their physicians. This approach is intended to create demand by changing patients' preferences for the benefits offered by the products. The role of health maintenance organizations (HMOs) in limiting access to specialists, to expensive investigations, and to such high-tech treatments as bonemarrow transplantation is under legislative assault as patients demand that their reasonable preferences be met.

It is important to emphasize that this review does not focus on the population level policy decisions reflected above but on the individual health care choices made by patients. In practice, physicians make decisions all day as they choose tests and treatments, select screening tests, and help patients manage chronic as well as life-threatening diseases. Most decisions are made in the face of uncertainty in the sense that the outcome of the action they select is unknown.

\section{Patient Decision Making}

The two key elements in any decision are (1) what is likely to happen, and (2) the value of the outcome to the decision maker. A patient's preference of one outcome for another is a direct reflection of the information available as well as values of the decision maker. Because the response to treatment is not absolutely guaranteed, these decisions are made

Submitted, revised, 18 January 1999.

From the Department of Family Practice, University of Washington School of Medicine, Seattle. Address reprint requests to Thomas $\mathrm{R}$. Taylor, MD, PhD, Department of Family Practice, Box 354696, University of Washington, Seattle, WA 98195-4696. in the uncertainty of whether the outcome might or might not be the desired one.

Physicians make the same kinds of decisions repeatedly. They develop a relatively stable understanding in their area of expertise of both the risks and benefits as well as the information needed in making satisfactory choices. When the decision making is controlled by the patient, however, a completely new set of circumstances comes into play.

Patients make any particular health care decision relatively infrequently, and most decisions are made with little preparation or repetition. As a result, patients cannot build up a stable understanding of the key elements of most of the decisions they make. Thus, in thinking about an illness and its treatment in the context of making advance directives for themselves or their parents, they are usually starting from scratch. The ways in which the choices are described, including the language chosen to describe possible outcomes, have a profound effect in framing such decisions and in influencing which options are eventually chosen. It is critically important that patients be given relevant, accurate information in a form that is amenable to influencing their preferences.

\section{Role of Preferences}

A woman with an intraductal carcinoma of the breast faces two main choices for its treatment: a simple mastectomy or a lumpectomy with radiation. In choosing one or the other, the patient is showing a preference for life after a simple mastectomy or life after a lumpectomy with radiation. The preference of one treatment rather than the other is a combination of how likely one or the other is to be successful and how the patient values the likely outcome of each treatment. According to the medical literature the probability of survival is about the same with each treatment. Because the outcome in either case is uncertain, the patient's preferences in this case are called utilities, because they reflect the 
patient's risk attitude or preference in the face of uncertainty.

By contrast, if the outcomes of a choice can be predicted with certainty, then the preferences are called values. Thus a patient with a hematologic malignancy might be asked whether he or she prefers 4 years without treatment to 8 years with repeated cycles of chemotherapy and transfusions. The patient would be asked to assume that each outcome would occur with certainty. Again, the patient is choosing one length and quality of life rather than another in the light of his or her relevant values.

\section{Do Preferences Really Exist?}

One of the other fundamental problems with eliciting patient preferences is the assumption that preferences already exist in the patient's mind, and that by presenting the patient with data in a particular way, we can elicit preferences. This concern has been raised by a number of authors. ${ }^{1}$ Lenert et $\mathrm{al}^{2}$ among the most active workers in this area, compared the way in which the preference elicitation task was described to the subjects. Two approaches were compared, namely, titration (steadily changing one option) and ping-pong (going back and forward between options). They found that on repeated testing, these two methods produced significantly different preference measurements, suggesting that preferences are strongly influenced by the elicitation process; indeed, they might even be created during the process of elicitation.

\section{Importance of Risk in Preference}

Decision making is acknowledged to be a process of balancing competing risks, eg, loss versus gain. ${ }^{3}$ Tversky and Kahneman ${ }^{4}$ have similarly shown that decisions involving uncertainty are influenced by whether the alternatives are perceived as gains or losses. Patients who shy away from more risky alternatives in favor of less risky alternatives are risk averse. If they are indifferent, they are risk neutral, and if they prefer risky situations, they are risk seeking.

The impact of differences in risk preferences within a family can be illustrated by a recent study of prostate cancer screening by Volk et al. ${ }^{5}$ Screening for prostate cancer is a utility-sensitive decision; the apparent gain in life expectancy from screening is small and patients might attach unusual impor- tance to certain outcomes of treatment, such as impotence or incontinence. This class of decision is one that Kassirer ${ }^{6}$ describes as appropriate for incorporating patient preferences.

The issue of who is the decision maker was also critical in the study by Volk et al. ${ }^{5}$ In some cases the husband had the final say, whereas in others the wife insisted (in the face of her husband's wishes to avoid unpleasant complications) that time together mattered more than anything. This latter stance reflects a value that quantity of life is more important than quality of life. It also reflects differences in risk perception between husbands and wives. In the above study, known evidence for and against prostate screening was assembled based on a recent decision analysis. ${ }^{7}$ The evidence summary (or balance sheet) included both short- and long-term complications of prostate cancer treatment. Longterm complications included complete impotence, urinary incontinence, urethral stricture, rectal injury, and complications related to hormone therapy. Short-term complications included gastrointestinal tract complications, thromboembolism, lymphedema, and radiation cystitis.

Preferences were assessed using the time tradeoff method (described below). The periods of time attached to each outcome reflected trade-offs between quantity and quality of life. Preferences were estimated separately for orchiectomy, because subjects associated particular importance to this procedure.

The study found that 9 of 10 wives preferred screening for their husbands, whereas 7 out of 10 husbands preferred no screening at all. Clearly, most husbands have a higher risk tolerance for this choice than their wives. Wives associated little burden with the complications of treatment and preferred to enhance their husbands' quantity of life regardless of the complications. The issue of who is the decision maker is paramount in the case of prostate screening, and optimal screening strategies might differ when viewed from the perspectives of the husband or wife.

The importance of risk preference for physicians has also been shown in a number of clinical situations. There is no doubt that similar effects could be found regarding patients' choices.

Physicians have been shown to exhibit variations in preferences for avoiding harmful medical actions. Some physicians are more sensitive to losses than to gains. Nightingale ${ }^{8}$ has shown that physi- 
cians in a general medical clinic who were loss averse on a risk preference scale ordered twice as many laboratory tests in hypothetical cases as their colleagues who were not as sensitive to loss. The more loss averse an emergency department physician, the more cases he admits to intensive care units, and the longer he continues resuscitation efforts after spontaneous contractions have ceased. ${ }^{8}$

\section{Effect of Framing on How Patients Use Information}

In the process of eliciting patient preferences, information has to be provided on the costs, benefits, complications, and outcomes of each treatment. A critically important feature of presenting choices to patients is the effect of framing. ${ }^{4,9}$ Thus choices can be presented to patients within a neutral, positive, or a negative frame. For example, we can provide patients with information about the probable outcomes of chemotherapy compared with surgery for cancer and about side effects and their impact on a patient's ability to function.

Using the same wording, a positive frame would emphasize how many would be free of side effects and who would survive. By contrast, the negative frame would emphasize those who would get undesirable side effects and those who would not survive. The neutral presentation gives equal emphasis to both good and bad outcomes.

Outcomes that are described positively in terms of ability to function and interaction with one's family, even for a short period of time, are more attractive to patients than are a longer time with a life limited by such side effects as nausea, bleeding, fatigue, or anorexia. Depending on the context in which a choice is presented, patients will make very different choices. ${ }^{10}$

\section{Importance of Clarifying Individual Patient Values}

Because preferences directly reflect the underlying values of the patient, there is a real possibility that individual patients will differ widely on which values they consider relevant to a particular decision.

The importance of exploring patients' perspectives before offering them choices was illustrated by a recent study by Pierce. ${ }^{11}$ In the context of selecting treatment for early-stage breast cancer, she focused on which attributes of the outcomes of treatment best reflected the values considered by women who are confronted with this choice. The options considered were simple mastectomy versus lumpectomy and radiation. The subjects were actual patients in this situation. It was assumed (for the sake of this comparison) that survival was comparable between the two options.

In the above study, 48 women were interviewed while making the above choice in a real-life situation and were asked to describe the attractive or unattractive features of each option. The results of this value clarification exercise showed that there were five principal dimensions of value in the choice between simple mastectomy and lumpectomy with radiation:

1. Expediency: was it quick and easy?

2. Safety: was there thorough eradication of the cancer?

3. Survival: how much did it extend the length of the patient's life?

4. Health: to what degree was the patient returned to normalcy?

5. Body integrity: keeping the breast or body intact.

The literature on patients' choices for breast cancer management does not address these individual attributes of the outcomes. Any attempt to elicit patients' preferences for these two procedures that did not explicitly address them would be unlikely to result in patient satisfaction. It remains to be seen whether another sample of patients with breast cancer would select the same attributes.

\section{Preference Elicitation and Role of the Balance Sheet}

It is important not to oversimplify the process by which human beings make decisions. Decisions are not made in a vacuum. Whereas many day-to-day decisions have to be made with very little information, most of us would agree that as much relevant information as possible should be available before making an important health-related decision. There is increasing patient interest in using information sources on the Internet to help them choose treatments, drug regimens, or surgical procedures. The emergence of many patient decision-support systems is an indication of this trend.

The process of eliciting preferences from a particular decision maker (whether patient or physi- 
cian) begins by assembling an evidence-based summary (a balance sheet) of the relevant information linking the options to the anticipated outcomes. The more personally involved the patient is in understanding the evidence, the more likely it will be that the preferences elicited will represent the patient's values and intentions.

A recent study of primary care patient preferences for methods of screening for colon cancer $^{12}$ illustrates the role of an evidence-based information summary in the form of a balance sheet (Table $1^{13-32}$ ) for assembling the evidence that a patient might consider in the rational examination of clinical preferences. The balance sheet organizes the information summary around five screening options. The balance sheet in this study was prepared using MEDLINE search references and data from the 1995 Office of Technology Assessment publication Cost-Effectiveness of Colorectal Cancer Screening in Average-Risk Adults. ${ }^{14}$ The screening options were those proposed by the American Gastroenterological Association.

In the above study, patients from the offices of primary care physicians listened to a scripted oral presentation while viewing a table supplemented by pie charts describing five screening methods and their outcomes. The patients were asked the following questions:

Considering the risks and benefits of colorectal cancer screening, if you were asked to select one of these options, which one would you choose?

Considering the risks and benefits of colorectal cancer screening, please evaluate how likely you would be to undergo each of the following (with each option listed to be ranked on a 5 -point Likert scale)?

I would want/I would not want to have this test if it were recommended by my physician (asked for each option).

The scaling method used in this study was a Likert scale for one question and a choice of best test and response to physician's recommendation for each option in turn. All these approaches would fall into the direct category scaling method (described below).

The important feature of this study is that it linked the evidence in the form of the literature reviews used in developing a guideline to the patients process of preference elicitation by the mech- anism of the balance sheet (Table 1). The study showed that $38 \%$ of patients chose colonoscopy as a preferred method of screening, $31 \%$ chose fecal occult blood test, $40 \%$ barium enema, and $13 \%$ flexible sigmoidoscopy.

The balance sheet is a list of possible outcomes that assists the patient or provider to make an informed decision regarding alternative interventions. ${ }^{33,34}$ An outcome is a benefit or harm to the patient, such as a potential complication, change in life expectancy, or pain or discomfort from a procedure. The balance sheet presents this information along with the probability that the outcome will occur for each option. By condensing the pertinent information onto a single, structured balance sheet, the patient or provider is able to consider more easily the possible outcomes before making a decision. The Agency for Health Care Policy and Research used a similar balance sheet to summarize the evidence from the literature reviews on benign prostatic hyperplasia from which the guideline was developed. ${ }^{35}$

\section{Role of Time and Time Trade-offs in Patient Preferences}

For some patients time in the context of making choices is not a uniform dimension. For example, they might be willing to put up with a great deal in the way of complications and side effects from a cancer treatment that would allow them to stay alive long enough to attend a daughter's wedding or the birth of a grandchild.

Perhaps one of the best examples of time tradeoffs is in the prevention of the complications of a chronic disease such as diabetes. It is not easy to convince patients that a lifetime dedicated to very tight control of their diabetes will have a conjectured improvement in outcomes such as small-vessel disease. For example, a very carefully controlled diet, a lot of exercise, and strict use of either an insulin pump or multiple daily shots of insulin will result in tight diabetes control with blood glucose levels kept well within or near the normal range. Trade-offs are that if the diabetes is controlled too tightly, there is a real danger of hypoglycemia, which is in many ways a more serious short-term complication than hyperglycemia. All this effort is directed at minimizing the progression of smallvessel disease manifested by renal failure, diabetic polyneuropathy, and ischemic heart disease. 
Table 1. A Balance Sheet of Colon Cancer Screening Tests Used in Study of Patient Preferences

\begin{tabular}{|c|c|c|c|c|c|}
\hline Event & $\begin{array}{l}\text { Without } \\
\text { Screening }\end{array}$ & $\begin{array}{c}\text { Fecal Occult Blood } \\
\text { Test }\end{array}$ & $\begin{array}{c}\text { Flexible } \\
\text { Sigmoidoscopy }\end{array}$ & Barium Enema & Colonoscopy \\
\hline Description of test & No testing & $\begin{array}{l}\text { You place } 2 \text { samples } \\
\text { of stool onto } \\
\text { special cards for } 3 \\
\text { consecutive days } \\
\text { and then mail } \\
\text { them to your } \\
\text { doctor for analysis }\end{array}$ & $\begin{array}{l}\text { A flexible tube with a } \\
\text { television camera } \\
\text { at the tip is placed } \\
\text { into your rectum } \\
\text { and can examine } \\
\text { approximately half } \\
\text { of your colon }\end{array}$ & $\begin{array}{l}\text { You are given an } \\
\text { enema of a liquid } \\
\text { that can be seen } \\
\text { on x-ray films. } \\
\text { Multiple x-ray } \\
\text { films are taken } \\
\text { with you lying in } \\
\text { different positions }\end{array}$ & $\begin{array}{l}\text { A flexible tube with a } \\
\text { television camera } \\
\text { at the tip is placed } \\
\text { into your rectum } \\
\text { and examines your } \\
\text { entire colon. If } \\
\text { polyps are found, } \\
\text { they can be } \\
\text { removed and } \\
\text { biopsied }\end{array}$ \\
\hline $\begin{array}{l}\text { Preparation required } \\
\text { for the test }\end{array}$ & None & $\begin{array}{l}\text { For } 5 \text { days you must } \\
\text { alter your diet so } \\
\text { as not to eat any } \\
\text { red meat, certain } \\
\text { fluids and } \\
\text { vegetables, or } \\
\text { vitamin C }\end{array}$ & $\begin{array}{l}\text { You must give } \\
\text { yourself } 2 \text { enemas } \\
1 \text { hour before the } \\
\text { procedure }\end{array}$ & $\begin{array}{l}\text { You must drink a } \\
\text { laxative solution } \\
\text { the evening before } \\
\text { the test, which } \\
\text { causes diarrhea to } \\
\text { clear your colon }\end{array}$ & $\begin{array}{l}\text { You must drink a } \\
\text { laxative solution } \\
\text { the evening before } \\
\text { the test, which } \\
\text { causes diarrhea to } \\
\text { clear your colon. } \\
\text { You cannot take } \\
\text { aspirin or } \\
\text { nonsteroidal anti- } \\
\text { inflammatory } \\
\text { medicines for 1 } \\
\text { week before the } \\
\text { procedure }\end{array}$ \\
\hline $\begin{array}{l}\text { Intravenous sedation } \\
\text { for test }\end{array}$ & No & No & No & No & Yes \\
\hline $\begin{array}{l}\text { Time required for } \\
\text { test }\end{array}$ & None & A few minutes & 15 minutes & 30 minutes & 45 minutes \\
\hline $\begin{array}{l}\text { Time missed from } \\
\text { work for test }\end{array}$ & None & None & $2-3$ hours & $2-3$ hours & Entire day \\
\hline $\begin{array}{l}\text { How often test } \\
\text { should be repeated }\end{array}$ & Not applicable & Every year & Every 3-5 years & Every 5 years & Every $5-10$ years \\
\hline $\begin{array}{l}\text { Likely discomfort } \\
\text { associated with the } \\
\text { test }\end{array}$ & None & $\begin{array}{l}\text { Process associated } \\
\text { with obtaining } \\
\text { stool samples from } \\
\text { toilet }\end{array}$ & $\begin{array}{l}\text { Mild sensation of } \\
\text { urge to have bowel } \\
\text { movement and } \\
\text { possibly crampy } \\
\text { abdominal pain }\end{array}$ & Mild abdominal pain & $\begin{array}{l}\text { Mild sensation of } \\
\text { urge to have bowel } \\
\text { movement and } \\
\text { possibly crampy } \\
\text { abdominal pan }\end{array}$ \\
\hline $\begin{array}{l}\text { Risk of making hole } \\
\text { in the colon, } \\
\text { which will require } \\
\text { hospitalization, } \\
\text { and might result } \\
\text { in surgery or death }\end{array}$ & 0 & 0 & $0-4 / 10,000^{13-16}$ & $0-4 / 10,000^{13-15,17}$ & $10-20 / 10,000^{13-15,18}$ \\
\hline $\begin{array}{l}\text { Probability of } \\
\text { developing colon } \\
\text { cancer of the rest } \\
\text { of one's life }\end{array}$ & $53 / 1000$ & $49 / 1000$ & $38 / 1000$ & $22 / 1000$ & $18 / 1000$ \\
\hline $\begin{array}{l}\text { Probability of dying } \\
\text { as a result of colon } \\
\text { cancer over the } \\
\text { rest of one's life }\end{array}$ & $25 / 1000$ & $19 / 1000$ & $14 / 1000$ & $7 / 1000$ & $6 / 1000$ \\
\hline $\begin{array}{l}\text { Colorectal cancers } \\
\text { prevented, \% }\end{array}$ & None & $10-38^{19-21}$ & $45^{22}$ & $40-70^{14}$ & $58-87^{23}$ \\
\hline $\begin{array}{l}\text { Decrease in } \\
\text { colorectal } \\
\text { mortality as a } \\
\text { result of screening } \\
\text { procedure, } \% .\end{array}$ & 0 & $20-33^{24,25}$ & $45-70^{22,26,27}$ & $45-70^{14}$ & $70-80^{26,28}$ \\
\hline $\begin{array}{l}\text { Chance that the } \\
\text { screening test will } \\
\text { be positive and } \\
\text { result in the need } \\
\text { for a colonoscopy } \\
\text { over } 10 \text { years, \% }\end{array}$ & 0 & $40^{24}$ & $8-13^{16,29-32}$ & $30-40^{15}$ & Not applicable \\
\hline $\begin{array}{l}\text { Unit cost per } \\
\text { procedure, } \$\end{array}$ & None & $5-10^{13,14}$ & $80-135^{13,14}$ & $121-200^{13,14}$ & $285-600^{13,14}$ \\
\hline
\end{tabular}

Reprinted with permission from Leard LE, Savides TJ, Ganiats TG. Patient preferences for colorectal cancer screening. J Fam Pract 1997;45:211-8. 
Patients differ in how much they take current account of the long-term consequences of their actions and the degree to which they can defer gratification, for example, by a tightly controlled diet to gain long-term benefits. So time and the length of the interval between the proximal actions and the distal outcomes is a very important part of patient preferences.

The effect of time on patient's preferences can be illustrated in another context. Christensen-Szalanski ${ }^{36}$ studied 18 pregnant women and their attitudes toward avoiding pain and avoiding the use of anesthesia during childbirth at three periods. One month before labor they were still consistently against pain avoidance. During early labor they were consistently against pain avoidance, but during active labor, however, there was a shift to favoring pain avoidance. One month postpartum they were again against pain avoidance. An important feature of this study was that the patients held opinions on outcomes that they had never experienced and changed their preferences in the light of experience, only to revert to previous preferences as memory of the labor pain faded. It is a useful study in emphasizing the distinction between current and longer term values.

\section{How Preferences Are Measured}

All research on measuring patient preferences has been conducted in highly structured experimental settings. Even in these settings the process of measurement is fraught with difficulties. A few studies (described above) have tried to move the measurement process into the real world of clinicians' offices, but the problems of translation are formidable. The precision demanded by the techniques described below is very difficult to sustain in the real-world interaction in a physician's office.

It is likely that techniques and instruments will be developed for specific common clinical problems (such as the colon or prostate cancer screening examples above), and then be adapted for use in physician's offices. What follows is a description of the methods and techniques that have emerged in the research world: the aim is to illustrate the complexities of preference measurement rather than provide a blue print for practice.

The process of eliciting preferences (for example, for colon cancer screening) begins with describing the key options (fecal occult blood test, flexible sigmoidoscopy, colonoscopy, barium enema) followed by assembling and framing the evidence in a form that is accessible and acceptable to patients. It culminates in the measurement and quantification of the preferences.

There are three widely used approaches for measuring or quantifying preferences, namely, the standard gamble, the time trade-off (TTO) and the rating scale approaches. The standard gamble is the only one that tries to measure utilities in the sense that the risk attitude of the patient is involved. The time trade-off and the rating scale approaches, as well as their variants, are used to measure values.

The standard gamble is the best known method and is derived directly from expected utility theory. Utility theory proposes among other assumptions that the rational decision maker will act to achieve the maximum expected overall utility or benefit.

The standard gamble poses a choice between a certain outcome and a gamble; for example, patients are asked to consider themselves as having congestive heart failure (American Heart Association classification II). They are asked to consider a gamble between staying at their current level of disability versus a gamble of $40 \%$ cure $(P=.40)$ or $100 \%$ to $40 \%(P=.06)$ chance of sudden death. The probability of cure is systematically varied until decision makers are indifferent between their current level of disability and a specific probability of cure. ${ }^{37}$ The probability level of cure at the point of indifference is a reflection of the utility that the decision maker attaches to cure. The standard gamble always poses a choice between a gamble and a certain outcome in which the certain outcome is intermediate in desirability between the best (cure) and worst (death) gamble outcomes.

The time trade-off method was developed by Torrance et $\mathrm{al}^{38}$ as a more easily understood alternative to the standard gamble. In this approach, patients are asked to choose between two certain outcomes (ie, the element of the gamble is omitted, so the preferences measured are values, not utilities, because no risk is involved). Patients are asked how many years in a healthy state would be equivalent to $x$ years in a poorer state of health. In this case, time is used as the unit of comparison; by comparing the two times, the utility or value for each outcome can then be calculated.

The third approach is the categorical rating scale. It is derived from the field of psychometrics and uses a scale anchored at each end. The patient 
defines the best (eg, perfect health) and worst (eg, death) states of health for either end of the scale. The patient then rates the desirability of the health states in question as points between the two extremes. For example, an interval scale of 10 categories is frequently used. The rating scale is the most widely used method for measuring health state preferences. ${ }^{39}$

There are three much less widely used categorical rating techniques that have been adopted to measure health state preferences. These techniques are aimed at improving on the category rating approach. One is the magnitude estimation, ${ }^{40}$ in which one outcome is taken as the standard and other outcomes are compared with this standard. For example, the standard is assigned a value of 10 , and the others are rated above or below it. Studies using this approach have produced inconsistent results. ${ }^{41}$

The second method is called equivalence, ${ }^{42}$ in which patients are asked how many patients in state $A$ are equivalent to 100 patients in state $B$. The third approach is called willingness-to-pay. ${ }^{43}$ In this exercise patients are told that a state of health, such as arthritis, is to be compared with perfect health. The patients are then asked what proportion of their household income would they be willing to pay to get from the state of arthritis to perfect health.

\section{Evaluating the Different Methods}

The standard gamble is very difficult to explain to physicians, let alone to patients, and is not intuitive. A number of studies, including those of LlewellynThomas et al,' have shown that changes in the gamble outcome significantly influenced the reported utilities for health states. This finding indicates that the standard gamble is internally inconsistent. Shoemaker ${ }^{44}$ has also reported extensive evidence to support this view. He found that persons using the standard gamble tend to provide utilities that are biased in the direction of risk aversion (ie, minimizing risk in their choices), leading to higher utility values than those derived from methods that do not involve gambles of any kind, such as the time trade-off or the category scaling.

Froberg and Kane ${ }^{41}$ conducted an extensive review of studies comparing the above six methods (standard gamble, time trade-off method, categorical rating scale, magnitude estimation, equivalence, willingness-to-pay). They reviewed a great many studies comparing various permutations of the above six methods and concluded that none of the methods are strictly comparable. They have concluded that the most promising methods are category scaling, magnitude estimation, and time trade-off. The category scaling method is the easiest to administer, is least expensive, and appears to yield scale values that are as valid as any other method. Thus, these authors recommend this method as a first choice, especially in large-scale studies. They advocate a more limited place for magnitude estimation and time trade-off approaches for studies that focus on decision making and are smaller in scale. The time trade-off approach is more difficult to administer and more expensive but has good validity levels.

These findings reflect that there is no way of knowing which of the number of different elicitation methods represents the reference standard. At this point, therefore, the most direct and straightforward technique, namely, the category scaling method, would appear to be most attractive.

Recently more standardized approaches have emerged because of the complex and time-consuming nature of the above approaches to eliciting preferences and attempting to quantify them. These standardized approaches are based on multiattribute utility theory (MAUT) ${ }^{45}$ It is regarded as being easy to understand and theoretically robust. It focuses on the utilities of decision makers rather than on probabilities. MAUT helps decision makers to break down the decision-making process into manageable segments and to evaluate the segments separately, and then it allows them to systematically recombine these segments to reach a decision.

The set of approaches described below use prescored multiattribute health status measures for which the key attributes are already described and have been standardized on a random sample of the public with scores derived for each response.

There are three well-known systems:

1. The Quality of Well-Being approach is scale based and therefore measures values. The respondents are asked to rate a single day on four attributes, namely, mobility, physical activity, social activity, and symptom-problem. If the patient has multiple symptoms or problems, then the patient rates the one that is most undesirable. ${ }^{46}$ 
2. The EuroQol system uses five attributes: mobility, self-care, usual activity, pain or discomfort, and anxiety or depression. This instrument was developed using a time trade-off technique and therefore yields values rather than utilities. It was standardized with a random sample of 3000 of the adult population of the United Kingdom. ${ }^{47}$

3. The Health Utilities Index is based in part on the Quality of Well-Being system. This instrument was developed using a time trade-off technique and therefore yields values rather than utilities. It was standardized on a random sample of residents of Hamilton, Ontario. A pediatric version has also been developed. ${ }^{48}$

All three approaches were developed for evaluating treatments and health care systems, such as neonatal intensive care (Health Utilities Index). Drummond et $\mathrm{a}^{49}$ have critically reviewed this set of approaches in some detail.

\section{When Should Patient Preferences Be Explicitly Assessed?}

Although eliciting the preferences of patients is a desirable goal, it is not practical in every clinical encounter, so some selectivity is appropriate. Choosing where to invest the effort is important. This issue has been dealt with in some detail by Kassirer. ${ }^{6}$

Among the most important decisions for which patient preferences should be explicitly assessed are (1) when there are major differences in the kinds of possible outcome (eg, death versus disability), (2) when there are major differences between treatments and the likelihood and impact of complications, (3) when choices involve trade-offs between near-term and long-term outcomes, (4) when one of the choices can result in a small chance of a grave outcome, (5) when the apparent differences between options is marginal, (6) when a patient is particularly adverse to taking risks, and (7) when a patient attaches unusual importance to certain possible outcomes.

\section{Physician and Patient Participation in Patient Preferences}

There is a sizable literature on the way in which decisions are made by patients in relation to their physicians.
There are wide differences among both physicians and patients as to the degree of control that patients should expect from their physicians in critically important decision making. There is the traditional paternalistic approach to decision making in which the physician knows best and advises the patient what ought to happen, and the patient merely concurs with the physician's analysis of the problem and the presentation of the choices. The choices in this context are those of the physician, not of the patient. Although patients might be allowed to choose, they are choosing from a menu of choices arrived at by physicians. Some such physicians see themselves as technocrats or experts and assume the reason patients come to see them is to be advised as to how they should proceed.

Some patients value and are comfortable with this approach, while other patients find it intolerable. A collaborative form of decision making involves the physician presenting the options to the patient, examining the situation with the patient to find out whether other options are available, and then presenting enough information for the patient to make a choice.

Understanding a patient's priorities and perspectives on important decisions is not only good clinical care but has been shown to result in better outcomes and improvements in patient satisfaction with care..$^{50}$ In a study of 117 patients in an HMObased general internal medicine practice, it was found that $47 \%$ of patients reported playing an active role in decision making, whereas $53 \%$ played a passive role. When compared with passive patients 1 week after a clinic visit, active patients described less discomfort, significantly greater reduction in symptoms, and more improvement in their general medical condition. When interviewed 7 days after the visit, active patients reported less concern with their illness, greater sense of control of their illnesses, and more satisfaction with its management.

Mort ${ }^{51}$ advocates a norm of collaborative decision making and cites studies of outcomes in breast cancer management, peptic ulcer disease, and diabetes to show that better participation leads to better outcomes. Peters ${ }^{52}$ has shown that the move away from medical paternalism necessitates the matching of information-gathering styles and decision-making styles of patients and their physicians. Patients vary in their perceived information needs; in their ability to acquire, process, and understand 
relevant medical information; and in their need for control in medical decisions.

\section{Conclusion}

Patient preferences are implicit to most of the practice of medicine. With the increasing degree of patients' participation in their own health care and their increasing financial responsibility, it becomes more important to understand how these preferences are generated, how they could be elicited, and how they can be brought to bear on important decisions, both in preventive and therapeutic medicine.

Almost all the applications in this overview have been developed for use in the evaluation of health systems or for research studies on how patients make important decisions. The studies by Leard et $\mathrm{al}^{12}$ and by Volk et $\mathrm{al}^{5}$ are the beginning of a move away from the research arena toward the day-today practice of medicine. Because the quantification of preferences by the techniques described above is only the end-stage of a process of decision making, it is likely that balance sheets and easily scored instruments will gradually emerge to help physicians participate with their patients in the informed decision making that an increasing number of patients demand.

\section{References}

1. Llewellyn-Thomas H, Sutherland HJ, Tibshirani R, Ciampi A, Till JE, Boyd NF. The measurement of patients' values in medicine. Med Decis Making 1982;2:449-62.

2. Lenert LA, Cher DL, Goldstein MK, Bergen MR, Garber A. The effect of search procedures on utility elicitations. Med Decis Making 1998;18:76-83

3. Eraker SA, Sox HC Jr. Assessment of patients' preferences for therapeutic outcomes. Med Decis Making 1981;1:29-39.

4. Tversky A, Kahneman D. The framing of decisions and the psychology of choice. Science 1981; 211:453-8.

5. Volk RJ, Cantor SB, Spann SJ, Cass AR, Cardems MP, Warren MM. Preferences of husbands and wives for prostate cancer screening, Arch Fam Med 1997;6:72-6.

6. Kassirer JP. Incorporating patients' preferences into medical decisions. N Engl J Med 1994;330:1895-96.

7. Cantor SB, Spann SJ, Volk, RJ, Cardenas MP, Warren MM. Prostate cancer screening: a decision analysis. J Fam Pract 1995;41:33-41

8. Nightingale SD. Risk preference and laboratory test selection. J Gen Intern Med 1987;2:25-8.
9. McNeil BJ, Pauker SG, Sox HC, Tversky A. On the elicitation of preferences for alternative therapies. N Engl J Med 1982;306:1259-62.

10. Siminoff LA, Fetting JH. Effects of outcome framing on treatment decisions in the real world: impact of framing on adjuvant breast cancer decisions. Med Decis Making1989;9:262-71.

11. Pierce $P F$. Defining and measuring personal values in breast cancer treatment decisions. In Toronto, Ontario: Proceedings of the Annual Meeting of the Society of Medical Decision Making, 1996:23.

12. Leard LE, Savides TJ, Ganiats TG. Patient preferences for colorectal cancer screening. J Fam Pract 1997;45:211-8.

13. Eddy DM. Screening for colorectal cancer. Ann Intern Med 1990:13:373-84.

14. Office of Technology Assessment. Cost-effectiveness of colorectal cancer screening in average-risk adults. Washington DC: Government Printing Office, 1995. Publication No OTA-BP-H 146.

15. Bond JH. Polyp guideline: diagnosis, treatment, and surveillance for patients with nonfamilial colorectal polyps. The Practice Parameters Committee of the American College of Gastroenterology. Ann Intern Med 1993;119:836-43.

16. McCallum RW, Meyer CT, Marignani P, Cane E, Contino $C$. Flexible sigmoidoscopy: diagnostic yield in 1015 patients. Am J Gastroenterol 1984;79:433-7.

17. Gelfand DW. Complications of gastrointestinal radiologic procedures: I. Complications of routine fluoroscopic studies. Gastrointest Radiol 1980;5:293315.

18. Waye JD, Lewis BS, Yessayan S. Colonoscopy: a prospective report of complications. J Clin Gastroenterol 1992;15:347-51.

19. Kewenter J, Bjork S, Haglind E, Smith L, Svanvik J, Ahren C. Screening and rescreening for colorectal cancer. A controlled trial of fecal occult blood testing in 27,700 subjects. Cancer 1988;62:645-51.

20. Kronborg O, Fenger C, Olsen J, Bech K, Sondergaard $O$. Repeated screening for colorectal cancer with fecal occult blood test. A prospective randomized study at Funen, Denmark. Scand J Gastroenterol 1989;24:599-606.

21. Hardcastle JD, Thomas WM, Chamberlain J, et al. Randomised, controlled trial of faecal occult blood screening for colorectal cancer. Results for first 107,349 subjects. Lancet 1989;1:1160-4.

22. Atkin WS, Cuzick J, Northover JM, Whynes DK. Prevention of colorectal cancer by once-only sigmoidoscopy. Lancet 1993;341:736-40.

23. Winawer SJ, Zauber AG, Gerdes H, Hornsby-Lewis $\mathrm{L}$, O'Brien MJ, Waye J. Reduction in colorectal cancer incidence following colonoscopic polypectomy. Report from the National Polyp Study (NPS). Gastroenterology 1991;100:A410.

24. Mandel JS, Bond JH, Church TR, et al. Reducing mortality from colorectal cancer by screening for 
fecal occult blood. Minnesota Colon Cancer Control Study. N Engl J Med 1993;328:1365-71.

25. Lieberman D. Screening/early detection model for colorectal cancer. Why screen? Cancer 1994;74(7 Suppl):2023-7.

26. Selby JV, Friedman GD, Quesenberry CP Jr, Weiss NS. A case-control study of screening sigmoidoscopy and mortality from colorectal cancer. $\mathrm{N}$ Engl J Med 1992;326:653-7.

27. Ransohoff DF. The case for colorectal cancer screening. Hosp Pract (Off Ed) 1994;29(8):25-32.

28. Newcomb PA, Norfleet RG, Storer BE, Surawicz TS, Marcus PM. Screening sigmoidoscopy and colorectal cancer mortality. J Natl Cancer Inst 1992;84: 1572-5.

29. Wherry DC. Screening for colorectal neoplasia in asymptomatic patients using flexible fiberoptic sigmoidoscopy. Dis Colon Rectum 1981;24:521-2.

30. Marks G, Boggs HW, Castro AF, Gathright JB, Ray JE, Salvati E. Sigmoidoscopic examinations with rigid and flexible fiberoptic sigmoidoscopes in the surgeon's office: a comparative prospective study of effectiveness in 1,012 cases. Dis Colon Rectum 1979; 22:162-8.

31. Lipshutz GR, Katon RM, McCool M, et al. Flexible sigmoidoscopy as a screening procedure for neoplasia of the colon. Surg Gynecol Obstet 1979;148:1922.

32. Shida H, Yamamoto T. fiberoptic sigmoidoscopy as the first screening procedure for colorectal neoplasms in an asymptomatic population. Dis Colon Rectum 1989;32:404-8.

33. Eddy DM. Comparing benefits and harms: the balance sheet. JAMA 1990;263:2493, 2498, 2501.

34. Eddy DM. Clinical decision-making: from theory to practice. Designing a practice policy. Standards, guidelines, and options. JAMA 1990;263:3077, 3081, 3084.

35. McConnell JD, Barry MJ, Bruskewitz RC. Benign prostatic hyperplasia: diagnosis and treatment. Quick reference guide for clinicians. Bethesda, Md: Agency for Health Care Policy and Research, 1994. [AHCPR publication No 94-0583.]

36. Christensen-Szalanski JJ. Discount functions and the measurement of patients' values. Women's decisions during childbirth. Med Decis Making 1984;4:47-58.

37. von Neumann J, Morgenstern O. Theory of games and economic behavior. New York: John Wiley, 1953.
38. Torrance GW, Thomas WH, Sackett DL. A utility maximization model for evaluation of health care programs. Health Serv Res 1972;7:118-33.

39. Torrance GW. Utility approach to measuring health-related quality of life. J Chronic Dis 1987;40: 593-603.

40. Stevens SS. Issues in psychophysical measurement. Psychol Rev 1971;78:426-50.

41. Froberg DG, Kane RL. Methodology for measuring health-state preferences - II: scaling methods. J Clin Epidemiol 1989;42:459-71.

42. Patrick DL, Bush JW, Chen MM. Methods for measuring levels of well-being for a health status index. Health Serv Res 1973;8:228-45.

43. Thompson MS. Willingness to pay and accept risk to cure chronic disease. Am J Public Health 1986; 76:392-6.

44. Schoemaker PJ. The expected utility model: its variants, purposes, evidence and limitations. J Econ Lit 1982;20:529-63.

45. Keeney RL, Raiffa H. Decisions with multiple objectives: preferences and value tradeoffs. New York: Cambridge University Press, 1993.

46. Kaplan RM, Anderson JP. The general health policy model: an integrated approach. In Spiker B, editor. Quality of life and pharmacoeconomics in clinical trials. Ind ed. New York: Raven Press, 1996:309-22.

47. Brooks R. EuroQol: the current state of play. Health Policy 1996;37:53-72.

48. Gold MR, Seigel JE, Russell LB, Weinstein MC. Cost effectiveness in health and medicine. New York: Oxford University Press, 1996.

49. Drummond MF, O'Brien B, Stoddart GL, Torrance GW. Methods for the economic evaluation of health care programmes. 2nd ed. New York: Oxford University Press, 1997

50. Brody DS, Miller SM, Lerman CE, Smith DG, Caputo GC. Patient perception of involvement in medical care: relationship to illness attitudes and outcomes. J Gen Intern Med 1989;4:506-11.

51. Mort EA. Clinical decision-making in the face of scientific uncertainty: hormone replacement therapy as an example. J Fam Pract 1996;42:147-51.

52. Peters MP. Matching physician practice style to patient informational issues and decision-making preferences. Arch Fam Med;1994:760-63. 